\title{
Judgment of rod verticality as a function of subject classification and frame pattern*
}

\author{
HENRY A. CROSS $\dot{\top}$ \\ Colorado State University, Fort Collins, Colo. 80521
}

Ss objectively classified as field-independent or field-dependent were given a "signal detection" modification of the rod-and-frame test. The rod was presented within the entire frame or within a "frame" consisting of only the corners or only the sides. The results indicate that field-dependent Ss differ from field-independents in both level and pattern of response and may attend to different aspects of the stimulus frame.

Although it has been suggested (e.g., Gross, 1959; Linton, 1965) that the Witkin rod-and-frame test (Witkin, Dyk, Faterson, Goodenough, \& Karp, 1962) may be contaminated by nonperceptual factors, Schuck, Cross, \& Mills (1970) failed to find evidence of this in their "signal detection" adaptation of this test with 8-11-year-old children. The "signal detection" approach was shown to be a useful procedure, and through its use Schuck et al isolated, in addition to the traditional field "independents" and "dependents," an intermediate or "other" S who behaved like a dependent under an 8-deg frame tilt but like an independent when the frame was tilted 28 deg.

Subsequently, Cross, Schuck, \& Dannemiller (1972), in a series of investigations, were able to show the three classifications with college students. They also found that the ability to correctly identify rod verticality was significantly increased for Ss classified as independents and others when the rod-and-frame exposure duration was increased from 10 to $1,000 \mathrm{msec}$. The reverse was true for dependents whose ability declined with increased duration. In addition, it was shown that although dependents were comparable to the other two categories in identifying rod verticality when only the rod was present, their performance was considerably disrupted even when the frame or "field" was terminated $2,500 \mathrm{msec}$ before rod presentation and subsequent verbal judgment.

This study continues the "signal detection" approach to the rod-and-frame test and is an attempt to determine if variously classified Ss are differently influenced by, or pay particular attention to, specific segments of the frame in the rod-and-frame test. The basic procedure involved the brief presentation of the rod within the traditional Witkin rod and frame and also within a frame condition consisting only of frame corners or, alternately, frame sides.

*This research was supported in part by a Faculty FIC grant, No. 0815 , from Colorado State University.

tThe author wishes to thank John Corona, Mary Cummings, Judd Sills, and Larry Walters, who assisted in the collection and analysis of data.

\section{METHOD}

The Ss were 12 paid undergraduate volunteers from Colorado State University. All had previoulsy served in similar rod-and-frame studies and were familiar with the four-category rating system employed. The Ss were chosen not only for their general understanding of the task, but also because they represented one of the three operationally defined classifications (see Schuck et al, 1970): dependents $(N=5)$, others $(N=4)$, and independents $(\mathrm{N}=3)$.

The apparatus was a large modified Witkin-type device that had frame dimensions of $40 \times 40 \times 1$ in. The rod was $36 \times 1$ in. The frame was made of green electroluminescent tape light (Sylvania Co.) and the rod was made of white tape light. The basic change in this apparatus over the one reported by Schuck et al (1970) was that it was constructed in such a way as to allow either the presentation of the entire frame, of only the corners, or of only the sides of the frame. Figure 1 is an actual photograph of the illuminated rod and frame taken in the darkened experimental room. The four side portions of the frame were each $24 \times 1$ in., and the corner portions were composed of overlapping 1 -in. tape light that extended $73 / 4$ in. from the intersection formed by the outside edges of the tape (see Fig. 1).

The basic procedure was essentially that which has been described elsewhere in detail (Schuck et al, 1970; Cross et al, 1972). The rod-and-frame exposure was brief, $50 \mathrm{msec}$, to insure that the visual sampling of $S$ would be restricted, and the line voltage into the tape light was $25 \mathrm{~V}$, which resulted in a luminescence level of $.03 \mathrm{fL}$.

On each of the 13 test days, each $S$ received 96 trials which were factorial combinations of two frame tilts, 8 and $28 \mathrm{deg}$, and three frame conditions-the entire frame, only the corners, and only the sides. On half of the test trials, the rod was vertical, and on the other 48 trials, the rod was tilted $4 \frac{1}{2} \mathrm{deg}$, always in the direction of the frame tilt. Figure 1 shows a frame tilt of $28 \mathrm{deg}$ with the rod tilted. Each of the six treatment conditions was

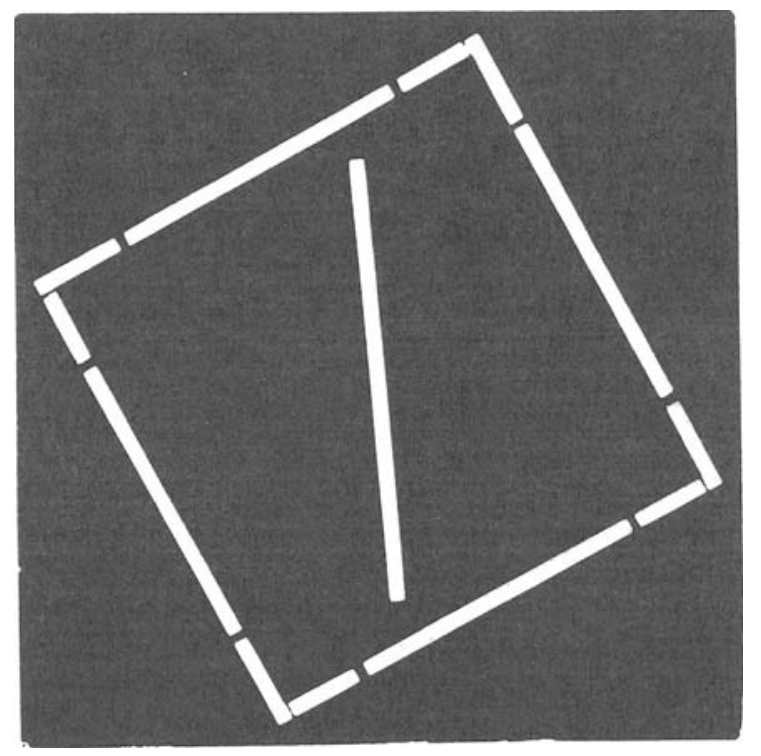

Fig. 1. A photograph of the illuminated rod and frame. The frame is tilted $28 \mathrm{deg}$ to the S's left. while the rod is tilted $4 \frac{1}{2}$ deg in the same direction. 
Table 1

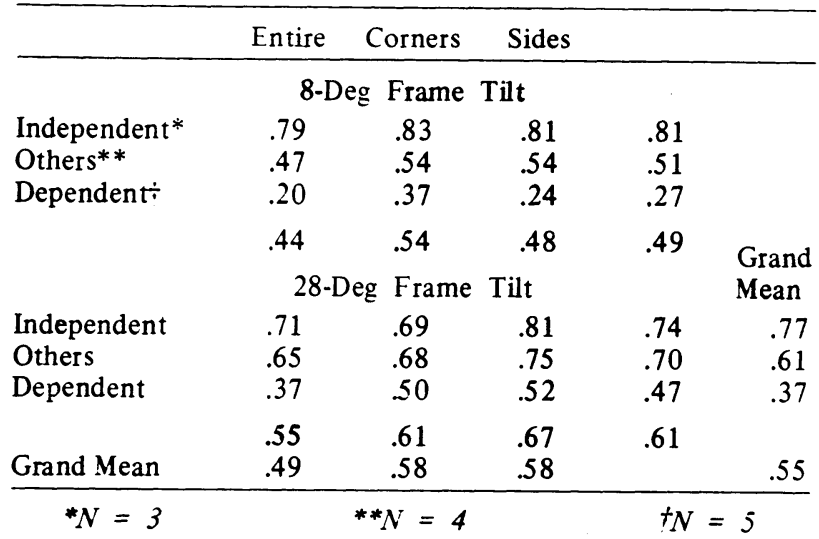

presented in 16-trial blocks, which were randomly determined separately for each S. Within each block, there were 8 trials with the frame tilted left and 8 trials to the right. Four of the 8 trials involved a vertical rod, while 4 employed a tilted rod. The 16 trials within each block were also determined randomly for each S. In summary, each $S$ received a total of 1,248 trials, or 208 (104 with the vertical rod and 104 tilted) in each basic treatment.

The S's task on each trial was to call out "yes" if he judged the rod to be vertical and "no" if he judged the rod to be tilted. In addition, he was asked to refine his judgment by also using either "sure" or "not sure" with each judgment.

The room itself was totally dark, and $\mathrm{S}$ was located behind a screen $10 \mathrm{ft}$ from the rod and frame. On signal, $S$ opened an aperture before him and was given a "ready" by $\mathrm{E}$ just before the exposure proper. After the exposure, S simultaneously closed the aperture in the screen and called out his judgment During the brief intertrial interval, approximately $15 \mathrm{sec}, \mathrm{E}$ recorded the responses and adjusted the rod and frame by use of a small pen light.

\section{RESULTS AND DISCUSSION}

The area under the ROC curve in the unit square was employed as a measure of S's ability to judge verticality, and this area measure served as the basic datum in a split-plot analysis of variance involving "classification of $S$ " as a nesting variable and both "frame condition" and "frame tilt" as repeated-measure variables. Table 1 summarizes the mean ROC data for all experimental conditions. The analysis of variance revealed a significant $(\alpha$ at least .05) influence due to classification, $F(2,9)=$ 17.40, and of Classification by Frame Tilt, $F(2,9)=$ 6.35. These findings simply reflect the classification system and are always found in the present approach to the rod-and-frame task.

The 28-deg frame tilt, as in all of our previous studies, was significantly easier than the 8-deg tilt, $F(2,9)=$ 15.13. There was also a significant effect attributable to "frame condition," $F(2,18)=12.16$, and there was a significant interaction involving "frame condition" and "frame tilt," $F(2,18)=40.83$. Finally, the interaction between classification and frame condition approached $(p=.0587)$ significance, $F(4,18)=2.77$.

Perhaps the most basic finding was that Ss were generally found to respond to frame segments in the same way that they respond to the entire frame. They do, in short, behave in accordance with their basic classification, which derived from the entire-frame condition. Beyond that, all Ss, even independents, perform most poorly under the entire-frame condition $(\bar{X}=.49)$ but equally under the corner-only $(.58)$ and sides-only (.58) conditions.

In the 8-deg condition, both independents and others, although starting at different levels, show some improvements in ability as they move from the entire frame to the other two frame conditions that are comparable in their effect. However, in the 28-deg condition both groups of Ss show comparable performance under the entire- and corner-frame conditions and a dramatic improvement under the side-frame condition. As in the previous studies, the independents and others were found to respond in a similar way in the 28-deg frame tilt. Dependents, on the other hand, while improving under both segmented conditions, do not show the marked jump under the sides condition. Dependents, in the 8-deg condition, show a dramatic improvement under the corners-only condition, but this is not the case for both independents and others.

It would appear that Ss classified as "other" are qualitatively similar to independents except that their performance under the 8-deg tilt fails to show significant sensitivity to the vertical condition. In the 28-deg condition, both others and independents are remarkably similar and would appear to be responding to the same stimulus elements. The dependent Ss, on the other hand, present a total picture that differs both in terms of level and pattern of response. This is putative evidence that different stimulus elements are being attended to; beyond that, a more specific interpretation is tenuous.

\section{REFERENCES}

Cross, H. A., Schuck, J. R., \& Dannemiller, E. Judgments of verticality as a function of exposure duration, liminance, frame-tilt and frame-rod interval. Psychonomic Science, 1972, 26, 65-68.

Gross, F. The role of set in perception of the upright. Journal of Personality, 1959, 27, 95-103.

Linton, $H$. Dependence on external influence and correlates in perception, attitudes and judgment. Journal of Abnormal \& Social Psychology, 1965, 51, 502-507.

Schuck, J. R., Cross, H. A., \& Mills, D. H. A signal detection analysis of the rod and frame test. Perception \& Psychophysics, 1970, 7, 276-280.

Witkin, H. A., Dyk, R. B., Faterson, H. F., Goodenough, D. R. \& Karp, S. A. Psychological differentiation. New Yodk: Wiley, 1962 .

(Received for publication April 6, 1973.) 